\title{
PERBEDAAN KARAKTERISTIK BPR KECIL DAN BPR MENENGAH DI NUSA TENGGARA BARAT
}

\author{
I Nyoman Nugraha Ardana Putra ${ }^{1}$, Dwi Putra Buana Sakti ${ }^{2}$, \\ I Gede Mandra $^{3}$, I Dewa Gede Bisma ${ }^{4}$, GA Sri Oktaryani ${ }^{5}$ \\ ${ }^{1}$ Fakultas Ekonomi dan Bisnis Universitas Mataram,ibobid@yahoo.com \\ ${ }^{2}$ Fakultas Ekonomi dan Bisnis Universitas Mataram, dwiputrabs39@gmail.com \\ ${ }^{3}$ Fakultas Ekonomi dan Bisnis Universitas Mataram, mandragede@yahoo.co.id \\ ${ }^{4}$ Fakultas Ekonomi dan Bisnis Universitas Mataram, idewagdebisma@unram.ac.id \\ ${ }^{5}$ Fakultas Ekonomi dan Bisnis Universitas Mataram,oktaryani@gmail.com
}

\begin{abstract}
ABSTRAK
Motivasi untuk dilakukan penelitian ini berawal dari adanya fenomena menunjukkan bahwa belum adanya aturan yang mengklasifikasikan BPR Kecil dan BPR Menengah seperti halnya pada UMKM dan Peraturan OJK yang baru. Penelitian ini bertujuan menggolongkan BPR dalam kategori kecil dan menengah. Penelitian dilakukan pada BPR di Propinsi NTB yang menggunakan pendekatan kuantitatif dan jenis penelitian komparatif dalam upaya membedakan karakteristik ukuran BPR. Data yang digunakan adalah data sekunder yang berasal dari laporan keuangan BPR dan publikasi lainnya baik dari pihak BPR maupun Bank Indonesia. Teknik analisis data dengan analisis kluster menggunakan program SPSS untuk mengklasifikasikan BPR yang ada. Hasil Menunjukkan bahwa dari keseluruhan BPR di NTB yaitu 29 buah BPR, ada 23 buah tergolong dalam BPR Kecil dan 6 buah masuk dalam kategori BPR Menengah. Selain itu ada perbedaan antara BPR Kecil Menengah.
\end{abstract}

Kata Kunci: BPR Kecil, BPR Menengah, dan Aset

\begin{abstract}
The motivation to the studies was started with the phenomenon shows there was no regulation on classifies small credit bank society (small BPR) and medium credit bank society (medium BPR) like a standard in small medium enterprises (SMES) and it's also new of OJK regulation. This study aims to classifies credit bank society in the category of small and medium enterprises. Location og this research is on province of West Nusa Tenggara that used a quantitative approach, with research is comparative in clasified size character of credit bank society. The data used is taken from secondary data derived from the reports on financial credit bank society and other publication the credit bank society and Bank of Indonesia as a central bank. Data analysis was the cluster analysis by SPSS to classify the credit bank society. Results show that of a whole of credit bank society in West Nusa Tenggara 29 unit, 23 unit classified as small credit bank society (Small BPR) and 6 unit as Medium credit bank society (Medium BPR). There are the difference between small BPR and medium BPR.
\end{abstract}

Keyword: small credit bank society, medium credit bank society, and assets

\section{PENDAHULUAN}

\section{Latar Belakang}

Usaha mikro, kecil dan menengah (UMKM) merupakan organisasi yang bertujuan menumbuhkan dan mengembangkan usahanya dalam rangka membangun perekonomian nasional berdasarkan demokrasi ekonomi yang berkeadilan. UMKM sebagai kekuatan Ekonomi Pancasila telah terbukti tahan banting ketika dihadapkan dengan krisis misalnya 
yang terjadi tahun 1998 dan 2008. Perusahaan yang tergolong kecil adalah usaha yang memiliki kekayaan bersih antara Rp. 50.000.000,- sampai dengan Rp. 500.000.000,(tidak termasuk tanah dan bangunan), atau memiliki penjualan Rp. 300.000.000,- sampai dengan Rp. 2.500.000.000,- (Undang-undang no.20 tahun 2008). Pada perusahaan menengah memiliki kriteria kekayaan Rp. 500.000.000,- sampai dengan Rp. 10.000.000.000,- atau memiliki penjualan Rp. 2.500.000.000,- sampai dengan Rp. 50.000.000.000,-. Semua usaha yang masuk kategori tersebut adalah usaha kecil dan menengah. Bank Perkreditan Rakyat (BPR) memiliki karakteritik yang berbeda dengan UMKM yang bergerak dalam industri perdagangan dan manufaktur, industri ini bergerak disektor jasa dalam bidang keuangan yang sering pula disebut Lembaga Keuangan Mikro (LKM) dan BPR pastinya tidak masuk dalam usaha mikro karena modal awal pendirian untuk didaerah antara Rp. 500.000.000 sampai Rp. 1.000.000.000,- (Peraturan Bank Indonesia, no. 8/26/PBI/2006).

Fenomena yang lagi banyak dibicarakan saat ini terkait dengan akan dilakukannya merger untuk kedua kalinya pada BPR kepemilikan pemerintah daerah (BUMD). Pemerintah Provinsi Nusa Tenggara Barat menargetkan penggabungan BPR NTB tuntas pada bulan Pebruari dan paling lama bulan Maret 2018 (Lombok Post, 2018). Sebenarnya bukan hanya penggabungan itu hal utamanya, akan tetapi terkait dengan perubahan bentuk badan usaha atau struktur kepemilikan dari bentuk Perusahaan Daerah (PD) menjadi Perseroan Terbatas (PT). Upaya swastanisasi atau privatisasi yang akan dilakukan oleh BPR kepemilikan pemerintah daerah ini terkait dengan pengelolaannya menjadi lebih profesional lagi yang tentunya dalam hal memperoleh laba sebesarbesarnya karena perusahaan swasta memang hanya berorientasi untuk memaksimumkan laba (profit oriented). Hal ini kemungkinan besar dengan adanya Peraturan Otoritas Jasa Keuangan nomor. 5 /POJK.03/2015 tentang penyediaan modal inti minimum bagi BPR adalah Rp. 6.000.000.000,- pada 31 Desember 2024 dan paling tidak pada tanggal 31 Desember 2019 sudah harus memiliki modal inti sebesar Rp. 3.000.000.000,-.

Dampak dari munculnya aturan tersebut salah satunya adalah penggabungan beberapa BPR dalam rangka memenuhi modal inti perusahaan. Sebelumnya di wilayah Nusa Tenggara Barat pada tahun 2009 telah terjadi proses merger terhadap 46 BPR yang tergolong dalam BPR Lumbung Kredit Pedesaan (BPR-LKP). BPR-LKP ini merupakan BPR yang dimiliki oleh Pemerintah Daerah sebagai bentuk Badan Usaha Milik Daerah (BUMD) dan Tujuan Penggabungan BPR-LKP ini adalah untuk meningkatkan efektivitas, efisiensi dan pengawasan (Putra, 2013). Selain itu penelitian Putra (2013) yang melakukan analisis perbedaan sebelum dan sedudah dilakukannya proses merger pada BPR-LKP ditinjau dari profitabilitas dan tingkat pengawasan. Hasil penelitian tersebut menggambarkan bahwa ada perbedaan kinerja ditinjau dari profitabilitas pada BPR-LKP sebelum dan sesudah merger, dimana setelah dilakukan merger justru kemampuan menghasilkan laba semakin kecil atau berkurang. Demikian pula dengan tingkat pengawasan pada BPR-LKP yang menggunakan proksi non performing loan (NPL), ternyata pasca dilakukannya merger justru kredit bermasalah yang dihadapi BPRLKP jauh semakin semakin besar, yang menunjukkan bahwa masalah yang dihadapi oleh BPR demikian komplek,

Salah satu dari delapan kendala yang dihadapi oleh BPR, berkaitan dengan efisiensi, yaitu biaya operasional (Putra, 2012) dan ternyata beberapa di Provinsi Jawa Timur, Bali dan Nusa Tenggara Barat menunjukkan bahwa secara umum BPR yang beroperasi pada wilayah tersebut memiliki efisiensi yang rendah. Hal yang menarik dari 
Anderson dan Ullah (2014) merekomendasikan agar perusahaan tetap dipertahankan kondisinya kecil (bahkan terkecil yang terbaik) dan yang jika diperbesar akan tidak menjamin keberlangsungan usahanya. Keunikan pada perusahaan keuangan yang ukurannya kecil ini menimbulkan motivasi untuk mengkaji secara mendetail batasan usaha kecil dan usaha menengah pada LKM serta mengetahui karakteristik BPR di NTB apakah sudah relevan dengan adanya Peraturan Otoritas Jasa Keuangan nomor. 5 /POJK.03/2015 tentang penyediaan modal inti minimum bagi BPR.

\section{Perumusan Masalah}

Berdasarkan latar belakang tersebut, dapat dirumuskan masalah sebagai berikut:

1. Manakah diantara BPR di NTB tersebut yang masuk kedalam kategori perusahaan kecil dan perusahaan menengah, ditinjau dari total aktiva?

2. Apakah ada perbedaan total aktiva antara peusahaan kecil dan menengah dari hasil pengklasifikasian data?

\section{Tujuan Penelitian}

Berdasar latar belakang masalah dan rumusan masalah tersebut dapat disusun tujuan penelitian sebagai berikut:

1. Untuk mengetahui BPR yang masuk dalam kategori kecil dan kategori menengah.

2. Untuk mengetahui perbedaan total aktiva dari hasil pengklasifikasian antara perusahaan kecil dan perusahaan menengah.

\section{Kerangka Teori}

Usaha Mikro, kecil dan Menengah merupakan pondasi dari ekonomi Pancasila yang terbukti sangat kokoh pada saat terjadinya krisis. Hal tersebut sesuai dengan UU No. 20 tahun 2008 terdapat tujuan pemberdayaan Usaha Mikro, Kecil, dan Menengah adalah mewujudkan struktur perekonomian nasional yang seimbang, berkembang, dan berkeadilan. Kestabilan perekonomian nasional sangat tergantung dari dari kondisi UMKM. Pemberdayaan UMKM juga dapat menumbuhkan dan mengembangkan kemampuan Usaha Mikro, Kecil, dan Menengah menjadi usaha yang tangguh dan mandiri, dimana saat ini banyak UMKM di Indonesia yang pangsa pasarnya merambah dunia internasional serta dapat bersaing dengan perusahaan nasional bahkan internasional. Melalui pemberdayaan dapat pula meningkatkan peran Usaha Mikro, Kecil, dan Menengah dalam pembangunan daerah, penciptaan lapangan kerja, pemerataan pendapatan, pertumbuhan ekonomi, dan pengentasan rakyat dari kemiskinan.

Batasan diantara perusahaan mikro, kecil dan menengah memang agak sulit dipilah-pilah. UU no. 20 tahun 2008 mengungkapkan beberapa kriteria yang tergolong usaha mikro, kecil dan menengah sebagai berikut.

1. Kriteria Usaha Mikro adalah sebagai berikut: a. memiliki kekayaan bersih paling banyak Rp50.000.000,00 (lima puluh juta rupiah) tidak termasuk tanah dan bangunan tempat usaha; atau b. memiliki hasil penjualan tahunan paling banyak Rp300.000.000,00 (tiga ratus juta rupiah).

2. Kriteria Usaha Kecil adalah sebagai berikut: a. memiliki kekayaan bersih lebih dari Rp50.000.000,00 (lima puluh juta rupiah) sampai dengan paling banyak Rp500.000.000,00 (lima ratus juta rupiah) tidak termasuk tanah dan bangunan tempat usaha; atau memiliki hasil penjualan tahunan lebih dari Rp300.000.000,00 (tiga ratus juta rupiah) sampai dengan paling banyak Rp2.500.000.000,00 (dua milyar lima ratus juta rupiah). 
3. Kriteria Usaha Menengah adalah sebagai berikut: a. memiliki kekayaan bersih lebih dari Rp500.000.000,00 (lima ratus juta rupiah) sampai dengan paling banyak Rp10.000.000.000,00 (sepuluh milyar rupiah) tidak termasuk tanah dan bangunan tempat usaha; atau b. memiliki hasil penjualan tahunan lebih dari Rp2.500.000.000,00 (dua milyar lima ratus juta rupiah) sampai dengan paling banyak Rp50.000.000.000,00 (lima puluh milyar rupiah).

\section{Aktiva BPR}

Sesuai dengan kriteria yang disampaikan dalam UU no. 20 tahun 2008 indikator untuk mengetahui ukuran perusahaan salah satunya adalah melalui total aktiva. Sebagian besar aset BPR tertanam dalam bentuk simpanan pihak ketiga. Ketika membahas tetang aset BPR maka tidak akan lepas dari istilah manajemen aktiva-pasiva dan sering disamakan pula dengan manajemen dana (fund management). Model manajemen aktiva dan pasiva sebenarnya digunakan untuk model-model perencanaan keuangan dalam manajemen dana yang bersifat jangka pendek yang bersifat harian sampai dengan 12 bulan(Taswan, 2010).

Manajemen dana (Fund Management) koordinasi hubungan timbal balik antara sumbersumber dan penggunaan dana berdasarkan keputusan dan rencana jangka pendek.

Beberapa item pembentuk aktiva dalam laporan keuangan BPR antara lain Kas, Kas dalam Valuta Asing, Surat Berharga, Pendapatan Bunga yang akan diterima, penempatan pada Bank lain dan penyisihan kerugian. Selain itu dalam aktiva juga terdapat jumlah kredit yang diberikan kepada BPR, Bank Umum, Non Bank- pihak terkait, Non Bank-pihak tidak terkait. Selanjutnya sebagai pembentuk aset juga terdapat penyisihan kerugian, agunan yang diambil alih, aset tetap dan inventaris, aset tidak berwujud dan aset lainya. Bentuk dari aktiva ini agak sedikit berbeda dengan jenis perusahaan pada umumnya karena BPR yang tergolong lembaga keuangan melakukan fungsi intermediasi yaitu menghimpun semua dana dari masyarakat umum dan kemudian menyalurkan kembali dana tersebut dalam bentuk kredit pada pihak-pihak yang membutuhkan.

\section{Penelitian Terdahulu}

Rana et al. (2016) menganalisis perbedaan antara bank syariah dan bank konvensional di Bangladesh periode 2013 sampai dengan 2014. Tujuan penelitian adalah membandingkan profitabilitas dan likuiditas antara kedua bank. Indikator profitabilitas yang digunakan antara lain ROAA, ROAE dan PEM, sedangkan likuiditasnya menggunakan pengukuran CR, LDR dan NLTA. Hasil penelitian mengindikasikan bahwa bank syariah di Bangladesh memiliki kinerja yang lebih baik dari bank konvensional yaitu secara profitabilitas, likuiditas dan efisiensi bank syariah sangat superior. El Masah dan Al-Sayed (2015) melakukan penelitian yang sama di Uni Emirat Arab (UEA), yang menggunakan data penelitian seluruh bank yang ada di UEA selama periode 2008 sampai dengan 2014. Bank tersebut terdiri dari 5 bank syariah dan 11 bank konvensional. Dalam mengukur kinerja bank-bank tersebut digunakan pengukuran profitabilitas, likuiditas, solvency dan risiko kredit. Hasil menggambarkan bank konvensional memiliki kondisi superior dibandingkan bank syariah dibandingkan bank syariah dilihat dari profitabilitas, risiko kredit dan solvency.

Berbeda dengan penelitian El Masah dan Al-Sayed (2015) yang hasilnya pada bank konvensional yang lebih besar memiliki kinerja yang lebih baik, begitu pula dengan penelitian Matthew dan Esther (2012). Penelitian ini dilakukan dengan membandingkan 
antara kinerja bank asing yang lebih besar, dengan bank yang lebih kecil yaitu bank lokal yang ada di Ghana. Beberapa variabel yang digunakan sebagai pembanding seperti Return on Asset, Return on Equity, Asset Quality, Capital Adequacy, Management Efficiency, Earning Performanace, Liquidity dan Bank Size. Bank yang berukuran lebih besar (bank asing), memiliki kinerja lebih baik ditinjau dari kecukupan modal, aset produktif, earning power (menghasilkan laba sebelum pajak) dan likuiditas. Hasil yang unik didapatkan ternyata bank lokal yang ukurannya lebih kecil memiliki kemampuan menghasilkan laba (sesudah pajak) lebih tinggi yang ditunjukkan dengan ROA dan ROE serta lebih baik dalam hal efisiensi.

Prabu dan Chandrasekaran (2015) melakukan studi komaparasi pada 2 bank di India yaitu State Bank of India (SBI) yang merupakan bank terbesar di Industri perbankan dan ICICI yang merupakan bank terbesar kedua di India. Mengunakan data sekunder sepanjang 2009 sampai dengan 2014. Hasil menunjukkan bahwa secara keseluruhan SBI memiliki kinerja yang lebih baik dibandingkan ICICI, namun ditinjau dari efisensi usahanya ternyata ICICI memiliki efisiensi yang lebih baik daripada SBI. Mistri dan Savani (2015) juga melakukan pengujian yang sama di India. Bedanya pada penelitian ini dilakukan terlebih dahulu klasifikasi atau penggolongan besar kecilnya perusahaan berdasarkan karakteristiknya berdasarkan aktiva dan pendapatan bunga. Pada tahap selanjutnya dilakukan penilian terhadap kinerja bank. Hasil penelitian menunjukkan semakin besar suatu bank akan meningkatkan efisiensi operasionalnya.

Ally (2013) menganalisis kinerja keuangan bank di Tanzania periode selama 7 tahun yaitu tahun 2006 sampai dengan tahun 2012. Digunakan pengukuran profitabilitas dengan indikator Return on Asset (ROA), Return on Equity (ROE) dan Net Interest Margin (NIM) dalam mengalisis kinerja bank. Alat analisis yang digunakan dalam menaganalisis perbedaan tersebut adalah Analysis of Varians (ANOVA) dengan mengukur rata-rata indikator yang digunakan sebagai perbandingan pada bank besar, bank menengah dan bank regional (bank kecil). Total ada sebanyak 28 bank yang digunakan sebagai sampel yang masing-masing terdiri dari 8 bank besar, 13 bank menengah dan 7 bank regional dan kecil. Hasilnya tidak ada perbedaan antar bank besar, menengah dan kecil dengan indikator ROA dan justru dengan indikator ROE dan NIM ternyata ada perbedaan antara ketiga jenis bank tersebut. Artinya masih terjadi kontroversi terkait dengan hasil dalam pengukuran profitabilitas ini. Menicucci dan Paolucci (2016) melakukan penelitian beberapa variabel yang mempengaruhi profitabilitas. Hal menarik dari penelitian ini ternyata salah satu variabel independennya adalah ukuran bank dan ternyata ukuran bank memiliki pengaruh positif terhadap profitabilitas. Artinya semakin besar ukuran bank, akan membuat kemampuan menghasilkan keuntungan (profitabilitas) yang tinggi pula. Helhel (2015) melakukan studi perbandingan proftabilitas antara bank asing dan bank domestik di Georgia selama periode 2009 sampai dengan 2013. Indikator yang digunakan antara lain ROA, ROE, NIM dan PEM pada 14 bank dan 9 diantaranya adalah bank asing dan 6 sisanya adalah bank lokal. Hasil pembandingan mengambarkan tidak adanya perbedaan antara bank asing dan bank domestik.

Divini dan Schiniotakis (2015) melakukan penelitian untuk membedakan bank yang tergolong menguntungkan (profitable) dan tidak menguntungkan (unprofitable) serta melihat pengaruhnya dari variabel umur, lokasi perusahaan, pendidikan, jumlah pelatihan, pengalaman kerja, dan evaluasi kinerja menggunakan analisis logit (logistic regression). Hasil penelitiannya menunjukkan bahwa perusahaan yang menguntungkan 
biasa memiliki karakteristik memiliki umur lebih tua (lebih lama berdiri), tempat usaha (lokasi) dan evaluasi kinerja.

Selanjutnya berdasarkan hipotesis yang telah tersusun, maka dapat dibangun kerangka konsep sebagai berikut

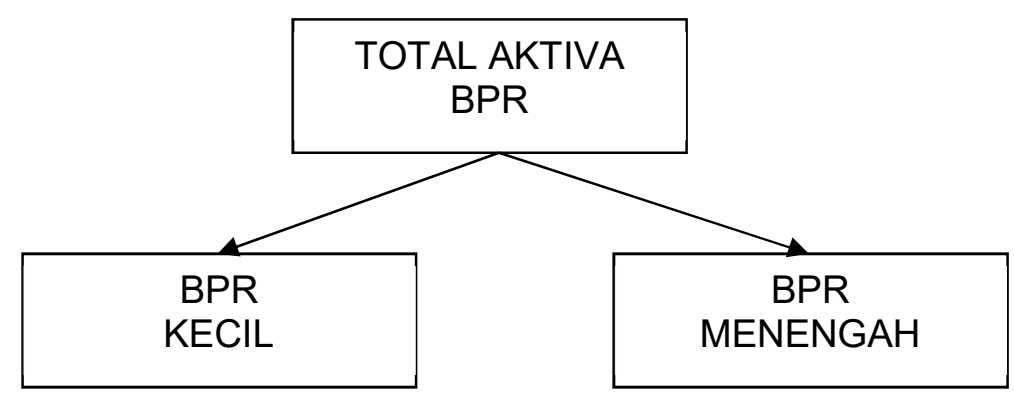

Gambar 1, Kerangka Konsep Penelitian

\section{METODE PENELITIAN}

\section{Jenis Penelitian}

Penelitian ini merupakan penelitian kuantitatif dengan jenis penelitian Deskriptif Komparatif, yang membandingkan antara BPR Kecil dan BPR Menengah. Penelitian ini diawali dengan membedakan karakteristik berdasarkan total aset.

\section{Lokasi Penelitian}

Penelitian ini dilakukan pada Lembaga Keuangan Mikro yaitu Bank Perkreditan Rakyat (BPR) yang ada di Provinsi Nusa Tenggara Barat (NTB) dibandingkan antara BPR Kecil dan BPR Menengah agar dapat memberikan sumbangan pemikiran tenatang kesehatan perbankan.Populasi dalam penelitian adalah seluruh BPR yang berada di provinsi NTB. Artinya metode pengumpulan data yang digunakan adalah sensus, sehingga semua perusahaaan atau BPR yang melaporkan laporan keuangannya per triwulan pada Bank Indonesia selama periode Maret, Juni, September dan Desember tahun 2015 dan tahun 2016, maka didapatkan 29 perusahaan yang ada dan BPR tersebut antara lain:

Tabel 1. BPR di Nusa Tenggara Barat

\begin{tabular}{|r|l|l|}
\hline NO & \multicolumn{1}{|c|}{ NAMA BPR } & \multicolumn{1}{c|}{ DAERAH OPERASIONAL } \\
\hline 1 & PT. BIMA ABDI SWADAYA & KABUPATEN BIMA \\
\hline 2 & PT.SAMAWA KENCANA & KABUPATEN SUMBAWA \\
\hline 3 & PT.DANA MASTER & KABUPATEN LOMBOK BARAT \\
\hline 4 & PT.DANAYASA & KABUPATEN LOMBOK BARAT \\
\hline 5 & PT.GRAHA LESTARI & KOTA MATARAM \\
\hline 6 & PT. KABALONG ABDI SWADAYA & KABUPATEN SUMBAWA \\
\hline 7 & PT.LOPOK GANDA & KABUPATEN SUMBAWA \\
\hline 8 & PT.NARPADA NUSA & KABUPATEN LOMBOK BARAT \\
\hline 9 & PT.PESISIR AKBAR & KABUPATEN BIMA \\
\hline
\end{tabular}




\begin{tabular}{|c|c|c|}
\hline NO & NAMA BPR & DAERAH OPERASIONAL \\
\hline 10 & PT.PITIH GUMARANG & KOTA MATARAM \\
\hline 11 & PT.PRIMANADI & KOTA MATARAM \\
\hline 12 & PT.RAMOT GANDA & KABUPATEN LOMBOK BARAT \\
\hline 13 & PT. PESISIR LAYAR BERKEMBANG & KABUPATEN LOMBOK BARAT \\
\hline 14 & PT.SEGARA ANAK KENCANA & KABUPATEN LOMBOK TIMUR \\
\hline 15 & PT.SAMAS & KABUPATEN LOMBOK TIMUR \\
\hline 16 & PT.SOWAN UTAMA & KABUPATEN LOMBOK TENGAH \\
\hline 17 & PT.TANJUNG ABDI SWADAYA & KABUPATEN LOMBOK UTARA \\
\hline 18 & PT.TRSNA NIAGA & KABUPATEN LOMBOK TENGAH \\
\hline 19 & PT.WIRANADI & KABUPATEN LOMBOK BARAT \\
\hline 20 & PT.ABDI WARGA MULYA & KABUPATEN LOMBOK BARAT \\
\hline 21 & PT.MITRA HARMONI & KOTA MATARAM \\
\hline 22 & PD. BPR NTB LOBAR & KABUPATEN LOMBOK BARAT \\
\hline 23 & PD. BPR NTB BIMA & KABUPATEN BIMA \\
\hline 24 & PD. BPR NTB DOMPU & KABUPATEN DOMPU \\
\hline 25 & PD. BPR NTB LOTENG & KABUPATEN LOMBOK TENGAH \\
\hline 26 & PD. BPR NTB LOTIM & KABUPATEN LOMBOK TIMUR \\
\hline 27 & PD. BPRNTB MATARAM & KOTA MATARAM \\
\hline 28 & PD, BPR NTB SUMBAWA BARAT & KABUPATEN SUMBAWA BARAT \\
\hline 29 & PD. BPR NTB SUMBAWA & KABUPATEN SUMBAWA \\
\hline
\end{tabular}

Sumber: Data Bank Indonesia, diolah

\section{METODE ANALISIS DATA}

Menurut Hair et al. (1995), analisis kluster membutuhkan dua tahapan yaitu, pertama mengukur kemiripan atau asosiasi diantara entitas untuk menentukan berapa banyak kelompok yang akan dipakai pada sampel. Kedua, memprofilkan orang atau variabel untuk menentukan posisinya. Pada intinya analisis kluster ini mengelompokan objek atau individu yang memiliki sifat dan karakteristikyang berdekatan. Pada prakteknya analisis kluster digunakan untuk segmentasi sejumlah konsumen (responden) kedalam beberapa kelompok (cluster) berdasarkan kemiripan sejumlah atribut yang didefinisikan. Metode kluster yang digunakan dalam analisis data ini adalah metode $K$ mean cluster. Alat analisis K-mean cluster adalah analisis statistik untuk mengelompokkan sejumlah objek kedalam sejumlah kelompok yang sudah ditetapkan dimana karakteristik objek hanya dikelompokkan berdasarkan variabel tertentu akan tetapi karakteristik latar belakang objek belum diketahui dengan pasti (Yamin dan Kurniawan; 2009). Dasar yang digunakan untuk membedakan antara BPR kecil dan BPR menegah adalah total aktiva dari masing-masing perusahaan.

Setelah didapatkan kelompok perusahaan atau BPR kecil dan BPR menengah melalui metode $K$-mean cluster, maka analisis dilanjutkan melalui uji perbandingan (analisis komparatif). Analisis perbandingan ini ada dalam tabel anova yang merupakan bagian dari output analisis kluster 


\section{HASIL PENELITIAN}

Dasar yang digunakan untuk membedakan antara BPR kecil dan BPR menengah adalah total aktiva (aset) dari masing-masing perusahaan.Hasil perhitungan analisis kluster dengan program SPSS melalui instrumen $K$ Mean Cluster adalah sebagai berikut:

Tabel 2. Jumlah Pengamatan yang Melalui Analisis Kluster

\begin{tabular}{|l|r|r|}
\hline \multirow{2}{*}{ Cluster } & 1 & 23,000 \\
\cline { 2 - 3 } & 2 & 6,000 \\
\hline Valid & 29,000 \\
\hline Missing &, 000 \\
\hline
\end{tabular}

Terlihat pengamatan yaitu ada 29 BPR di Nusa Tenggara Barat yang dibedakan ukurannya melalui proxy aset (total aktiva). Hasil pengklasifikasian tersebut menunjukkan bahwa berdasarkan total aktiva terdapat 6 perusahaan (BPR) berskala Menengah (nomor 2) dan ada 23 BPR berukuran kecil (nomor 1). Jadi nomor 1 adalah simbol untuk BPR Kecil dan 2 simbol pada BPR Menengah.

Selain tabel tersebut ada tabel output penting lainnya dalam rangka mengetahui sampel mana saja yang merupakan BPR yang tergolong kecil dan BPR yang tergolong menengah, yaitu dengan mengamati Tebel 3. Berikut.

Tabel 3. Cluster Membership

\begin{tabular}{|l|r|r|}
\hline Case Number & Cluster & \multicolumn{1}{c|}{ Distance } \\
\hline 1 & 1 & 16319487,304 \\
\hline 2 & 2 & 10694368,333 \\
\hline 3 & 1 & 15619134,696 \\
\hline 4 & 1 & 8689684,696 \\
\hline 5 & 1 & 11472909,696 \\
\hline 6 & 1 & 9475654,696 \\
\hline 7 & 1 & 5354472,696 \\
\hline 8 & 1 & 5099355,696 \\
\hline 9 & 1 & 22954757,304 \\
\hline 10 & 1 & 2983139,304 \\
\hline 11 & 2 & 73158817,667 \\
\hline 12 & 1 & 3226257,696 \\
\hline 13 & 2 & 46999475,333 \\
\hline 14 & 1 & 12977547,696 \\
\hline 15 & 1 & 10444576,696 \\
\hline 16 & 1 & 11467602,696 \\
\hline 17 & 1 & 5406091,304 \\
\hline 18 & 1 & 1444882,304 \\
\hline 19 & 1 & 12038371,696 \\
\hline 20 & 1 & 4736601,696 \\
\hline 21 & 1 & 17203885,696 \\
\hline 22 & 1 & 46614601,304 \\
\hline 23 & 1 & 37972022,304 \\
\hline 24 & 2 & 4865543,333 \\
\hline
\end{tabular}




\begin{tabular}{|l|r|r|}
\hline \multicolumn{1}{|c|}{ Case Number } & \multicolumn{1}{c|}{ Cluster } & \multicolumn{1}{c|}{ Distance } \\
\hline 25 & 2 & 24008900,333 \\
\hline 26 & 1 & 2799794,304 \\
\hline 27 & 1 & 629437,304 \\
\hline 28 & 2 & 13409469,667 \\
\hline 29 & 1 & 9318156,696 \\
\hline
\end{tabular}

Terlihat bahwa ada 6 BPR yang termasuk dalam kategori besar (pada tabel dari inisial 2) yaitu BPR dengan nomor urut 2, 11, 13, 24, 25 dan 28. Artinya beberapa BPR yang masuk dalam kategori menengah adalah PT. BPR Samawa Kencana, PT BPR Prima Nadi, PT. BPR Segara Anak Kencana, PD. BPR NTB LOTENG, PD. BPR NTB LOTIM dan PD. BPR NTB Samawa. Sisanya sebanyak 23 BPR masuk dalam klasifikasi BPR yang relatif Kecil. BPR yang tergolong kecil adalah terlihat pada Tabel Berikut:

Tabel 4. Daftar BPR yang Termasuk Dalam Klasifikasi BPR Kecil

\begin{tabular}{r|l|l|}
\hline \multicolumn{1}{|c|}{ NO } & \multicolumn{1}{|c|}{ NAMA BPR } & \multicolumn{1}{c|}{ DAERAH OPERASIONAL } \\
\hline 1 & PT. BIMA ABDI SWADAYA & KABUPATEN BIMA \\
\hline 2 & PT.DANA MASTER & KABUPATEN LOMBOK BARAT \\
\hline 3 & PT.DANAYASA & KABUPATEN LOMBOK BARAT \\
\hline 4 & PT.GRAHA LESTARI & KOTA MATARAM \\
\hline 5 & PT. KABALONG ABDI SWADAYA & KABUPATEN SUMBAWA \\
\hline 6 & PT.LOPOK GANDA & KABUPATEN SUMBAWA \\
\hline 8 & PT.NARPADA NUSA & KABUPATEN LOMBOK BARAT \\
\hline 9 & PT.PITIH GUMARANG & KABUPATEN BIMA \\
\hline 10 & PT.RAMOT GANDA & KOTA MATARAM \\
\hline 11 & PT.SEGARA ANAK KENCANA & KABUPATEN LOMBOK BARAT \\
\hline 12 & PT.SAMAS & KABUPATEN LOMBOK TIMUR \\
\hline 13 & PT.SOWAN UTAMA & KABUPATEN LOMBOK TIMUR \\
\hline 14 & PT.TANJUNG ABDI SWADAYA & KABUPATEN LOMBOK UTARA \\
\hline 15 & PT.TRSNA NIAGA & KABUPATEN LOMBOK TENGAH \\
\hline 16 & PT.WIRANADI & KABUPATEN LOMBOK BARAT \\
\hline 17 & PT.ABDI WARGA MULYA & KABUPATEN LOMBOK BARAT \\
\hline 18 & PT.MITRA HARMONI & KOTA MATARAM \\
\hline 19 & PD. BPR NTB LOBAR & KABUPATEN LOMBOK BARAT \\
\hline 20 & PD. BPR NTB BIMA & KABUPATEN BIMA \\
\hline 21 & PD. BPR NTB LOTIM & KABUPATEN LOMBOK TIMUR \\
\hline 22 & PD. BPRNTB MATARAM & KOTA MATARAM \\
\hline 21 & PD. BPR NTB SUMBAWA & KABUPATEN SUMBAWA \\
\hline & & \\
\hline
\end{tabular}

Terlihat pada Tabel 2, Tabel 3 dan Tabel 4 menunjukan bahwa BPR di Nusa tenggara Barat didominasi oleh BPR yang masuk dalam klasifikasi kecil. Sebanyak 21 BPR dari total 29 BPR yang menjadi sampel penelitian termasuk kategori kecil dan siasnya ada 6 BPR masuk dalam kategori menengah. 
Selanjutnya dilakukan uji beda dari hasil pengklasifiakasian tersebut. Salah satu tabel output SPSS ketika melakukan analisis cluster adalah pembandingan antara klusterkluster yang terbentuk. Komparasi tersebut berupa tabel ANOVA yang dapat dilihat pada Tabel 5. berikut ini.

Tabel 5. Hasil Komparasi dengan Analisis of Varians (ANOVA)

\begin{tabular}{|c|c|c|c|c|c|c|}
\hline & \multicolumn{2}{|l|}{ Cluster } & \multicolumn{2}{|l|}{ Error } & \multirow[t]{2}{*}{$\mathbf{F}$} & \multirow[t]{2}{*}{ Sig. } \\
\hline & Mean Square & Df & Mean Square & Df & & \\
\hline ASET & $\begin{array}{r}5358268044280812 \\
8,000\end{array}$ & 1 & $\begin{array}{r}536187955840209 \\
, 200\end{array}$ & 27 & 99,933 &, 000 \\
\hline
\end{tabular}

Tabel 5 menggambarkan bahwa hasil pembandingan atau komparasi antara BPR Kecil dengan BPR Menengah yang merupakan hasil dari analisis cluster ditunjukan dengan FHitung sebesar 99,933 dan tingkat signifikansi sebesar 0,000. Artinya nilai signifikansi sebesar 0,000 jika dibandingkan dengan tingkat kesalahan 5\% $(0,05)$ maka terdapat perbedaaan antara BPR yang termasuk dalam kategori kecil dibandingkan dengan BPR yang termasuk dalam kategori menengah, dan hal ini berarti menerima Ha seperti dalam uji hipotesis statistik berikut:

H0: Tidak ada perbedaan antara cluster 1 dengan cluster 2 ditinjau dari total aset

Ha: Ada perbedaan antara cluster 1 dengan cluster 2 ditinjau dari total aset

Nilai signifikansi $0,000<0,05$ yang berarti hipotesis nul $(\mathrm{H} 0)$ ditolak dan menerima hipotesis alternatif (Ha) yang berbunyi ada perbedaan antara cluster 1 dengan cluster 2 ditinjau dari total aset.

\section{PEMBAHASAN}

Ada 6 BPR di NTB yang tergolong dalam BPR Menengah yaitu PT. BPR Samawa Kencana, PT. BPR Prima Nadi, PT. BPR Segara Anak Kencana, PD. BPR NTB LOTENG, PD. BPR NTB LOTIM dan PD. BPR NTB Samawa. Sisanya sebanyak 23 BPR masuk dalam klasifikasi BPR yang relatif Kecil. Berdasarkan aturan secara umum BPR tersebut telah memiliki aset diatas rata-rata yaitu Rp. 18.738.209.000,- dan tentunya memiliki modal inti dibawah itu dan tergolong cukup. Secara umum baik BPR Kecil maupun BPR Menengah telah memiliki total aset rata-rata senilai Rp. 40.692.778,- yang berarti BPR-BPR yang ada di Provinsi Nusa Tenggara Barat telah memiliki total aset yang cukup besar dan secara umum siap menghadapi peraturan dari OJK.

Ada satu BPR yang tergolong kecil memiliki tugas yang cukup berat dalam menghadapi Peraturan Otoritas Jasa Keuangan nomor. 5 /POJK.03/2015 tentang penyediaan modal inti minimum bagi BPR adalah Rp. 6.000.000.000,- pada 31 Desember 2024 dan paling tidak pada tanggal 31 Desember 2019 sudah harus memiliki modal inti sebesar Rp. 3.000.000.000,- Hal tersebut karena sampai saat ini BPR yang bersangkutan hanya memiliki total aset dibawah Rp. 3.000.000.000 yang berarti modal intinya jauh dibawah nilai tersebut.

Hasil dari penggolongan atau pengklasifikasian menggunakan analisis cluster tersebut juga langsung dibedakan dengan antara cluster 1 (BPR Kecil) dengan cluster 2 (BPR Menengah). Komparasi atau perbandingan antara total aset BPR Kecil dan BPR 
Menengah dianalisis dengan analysis of variance (anova). Hasil tersebut menunjukan bahwa ada perbedaan antara total aset BPR Kecil dengan BPR Menengah dan hal tersebut terbukti bahwa rata-rata total aset BPR Kecil sebesar Rp. 18.738.209,- dan untuk BPR Menengah memiliki total aset Rp. 124.851.961.000,-. Hasil penelitian Anderson dan Ullah (2014) menyatakan bahwa supaya perusahaan-perusahan tetap mempertahankan kondisinya ukurannya yang relatif kecil (bahkan terkecil yang terbaik) dan yang jika diperbesar akan tidak menjamin keberlangsungan usahanya. Hal tersebut karena ketika berubah menjadi menengah atau besar dapat merubah struktur oraganisasi dalam perusahaan dan image yang ditimbulkan dengan perubahan ukuran perusahaan pada pelanggan yang menjadi pindah menjadi pelanggan produk pesaing.

\section{KESIMPULAN}

Berdasarkan hasil analisis, maka dapat disimpulkan bahwa:

1. BPR dapat dibedakan menjadi BPR Kecil dan BPR Menengah berdasarkan total aktiva yang dimiliki. Ada 6 BPR di NTB yang tergolong dalam BPR Menengah yaitu PT. BPR Samawa Kencana, PT. BPR Prima Nadi, PT. BPR Segara Anak Kencana, PD. BPR NTB LOTENG, PD. BPR NTB LOTIM dan PD. BPR NTB Samawa. Sisanya sebanyak 23 BPR masuk dalam klasifikasi BPR yang relatif Kecil. Berdasarkan aturan secara umum BPR tersebut telah memiliki aset diatas rata-rata yaitu Rp. 18.738.209,- dan tentunya memiliki modal inti dibawah itu dan tergolong cukup. Ada satu BPR yang tergolong kecil memiliki tugas yang cukup berat dalam menghadapi Peraturan Otoritas Jasa Keuangan nomor. 5 /POJK.03/2015 tentang penyediaan modal inti minimum bagi BPR adalah Rp. 6.000.000.000,- pada 31 Desember 2024 dan paling tidak pada tanggal 31 Desember 2019 sudah harus memiliki modal inti sebesar Rp. 3.000.000.000,- Hal tersebut karena sampai saat ini BPR yang bersangkutan hanya memiliki total aset dibawah Rp. 3.000.000.000 yang berarti modal intinya jauh dibawah nilai tersebut.

2. Ada perbedaan antara BPR Kecil dengan BPR Menengah dari hasil pengklasifikasian data. Hal tersebut disebabkan sebagian besar BPR di NTB didominasi oleh BPR yang masuk dalam kategori kecil .

\section{DAFTAR PUSTAKA}

, 2006, Peraturan Bank Indonesia no. 8/26/PBI/2006 Tentang Bank Perkreditan Rakyat. ,2008, Undang-Undang no. 20 tahun 2008 Tentang Usaha Mikro, Kecil dan Menenggah, Kementrian Hukum dan Hak Asasi Manusia.

2015, Peraturan Otoritas Jasa Keuangan No. 5/POJK.03/2015, Tentang Kewajiban Penyediaan Modal Minimum dan Pemenuhan Modal Inti Minimum Bank Perkreditan Rakyat.

, 2018, Bulan Depan Ditarget Rampung, "Penggabungan PT. BPR NTB”, Lombok Post,29 Januari 2018, Halaman 8, Kolom 6-8.

Ally, Z., 2013, Comparative Analysis of Financial Performance of Commercial Banks in Tanzania, Research Journal of Finance and Accounting, Vol.4, No.19, pp. 133-144 
Anderson, Alistair R., dan Farid Ullah, 2014, The condition of smallness: how what it means to be small deters firms from getting bigger, Management Decision, Vol. 52 Iss 2 pp. $326-349$.

Divini, Aikaterini dan Nikos Schiniotakis, 2015, Performance and profile: a twofold bank profitability riddle, Team Performance Management, Vol. 21 No. 1/2, pp. 5164.

El Masah, S., dan O. Al-Sayed, 2015, Banking Sector Performance: Islamic And Conventional Banks In The UAE, International Journal of Technology Information and Business Management, Vol.36 no.1, pp. 69-81.

Hair, J.F., R.E. Anderson, R.L. Tatham dan W.C. Black, 1995, Multivariate Data Analysis With Readings, 4th edition, Englewood Cliffs, NJ: Prentice Hall International.

Helhel, Y., 2015, Comparative Analysis of Financial Performance of Foreign and Domestic Banks in Georgia, International Journal of Finance and Accounting, 4(1): pp. 52-59.

Mathew, N.G., dan L.A. Esther, 2012, A Financial Performance Comparison of Foreign VS Local Banks in Ghana, International Journal of Business and Social Science, Vol. 3 No. 21, pp. 82-87.

Menicucci, E., dan G. Paolucci , (2016),"The determinants of bank profitability: empirical evidence from European banking sector", Journal of Financial Reporting and Accounting, Vol. 14 Iss 1

Prabu, G.G. dan G. Chandrasekaran, 2015, A Comparative Study on Financial Performance of State Bank of India and ICICI Bank, International Journal of Research in Business Management, Vol. 3, Issue 4, Apr 2015, pp.19-26

Putra, I.N.N.A., 2012, Kepemilikan Manajerial dan Risiko Kredit Sebagai Pemicu Biaya Keagenan Pada Lembaga Keuangan Mikro, Jurnal Keuangan dan Perbankan, vol.16, no.3, 437-444.

Putra, I.N.N.A., 2013, Perbedaan Profitabilitas Dan Tingkat Pengawasan Sebelum Dan Sesudah Merger Pada Bank Perkreditan Rakyat, Jurnal Keuangan dan Perbankan, vol. 17, no.2, 302-309.

Rana, M, M.K. Hossain, dan R.S. Rekha, 2016, Profitability and liquidity of conventional banking and Islamic banking in Bangladesh: A comparative study, International Journal of Applied Research, no. 2(9), pp. 318-327.

Taswan, 2010, Manajemen Perbankan, Konsep, Teknik dan Aplikasi, UPP STIM YKPN, Yogyakarta.

Yamin, S. Dan Kurniawan H., 2009, SPSS Complete: Teknik Analisis Statistik Terlengkap dengan Software SPSS, Salemba Infotek, Jakarta. 